\title{
Epidemiological and clinical features of primary herpes simplex virus ocular infection
}

\author{
S DAROUGAR, M S WISHART, AND N D VISWALINGAM
}

From the Subdepartment of Virology, Institute of Ophthalmology; and the External Eye Diseases Clinic, Moorfields Eye Hospital, London

SUMmaRY The epidemiological and clinical features of primary herpes simplex virus ocular infection in 108 patients were studied. Of these, $69(64 \%)$ were aged 15 or over and only eight (7\%) were under the age of 5 . Associated upper respiratory tract infection was found in $38(35 \%)$ patients and systemic disorders such as mild malaise, fever, and aching in $34(31 \%)$ patients. Common symptoms were redness, watering, discharge, itching, irritation, and lid swelling, whereas pain, photophobia, lid vesicles and ulcers, and blurred vision were less frequent. The major signs consisted of vesicles and ulcers on the lids, papillary responses which were more severe in the upper lid conjunctiva, follicles which were more common in the lower lid conjunctiva, fine and coarse epithelial punctate keratitis, and subepithelial punctate keratitis. Dendritíc ulcers and disciform keratitis were found in $16(15 \%)$ and two $(2 \%)$ patients respectively. The clinical forms of primary herpes simplex virus ocular infection varied. Moderate or severe disease was observed in $41(38 \%)$ and $16(15 \%)$ patients respectively. In eight $(7 \%)$ patients the disease presented as an acute follicular conjunctivitis without characteristic lid or corneal lesions. A chronic blepharoconjunctivitis which lasted for months developed in $16(15 \%)$ patients. The epidemiological and clinical features in our patients were compared with features of the disease reported previously.

Herpes simplex virus (HSV) ocular infection is the major cause of corneal blindness in developed countries. In developing countries it is becoming more prevalent, causing more blindness.

HSV ocular infection may present in various clinical forms. Acute blepharoconjunctivitis with or without keratitis, recurrent corneal ulcers, and recurrent stromal keratitis are common forms of the disease.' Primary ocular infection may present as an acute follicular conjunctivitis or keratoconjunctivitis with or without characteristic lid or corneal lesions. ${ }^{2}$ In recent years we have observed changes in the epidemiological and clinical features of primary HSV ocular infection in patients attending the External Eye Diseases Clinic at Moorfields Eye Hospital. In this report we present the major features of primary HSV ocular infection observed in 108 patients and compare these with the features of the disease reported previously.

Correspondence to Professor S Darougar, Institute of Ophthalmology, Judd Strect, London WC1H 9QS.

\section{Patients and methods}

One hundred and eight patients attending the External Eye Diseases Clinic, Moorfields Eye Hospital, during the period 1973-80 were studied. These patients, who had no previous history of HSV ocular infection, presented with acute conjunctivitis associated with either characteristic HSV lid lesions (vesicles and/or ulcers), or typical corneal lesions (ulcers or stromal keratitis) or were HSV isolation positive.

The patients were examined with a Haag-Streit slit-lamp. Symptoms and signs were graded on a 0 to 3 scale (absent, mild, moderate, severe) ${ }^{3}$ Swabbings for HSV isolation were taken from the upper and lower lid conjunctivae, placed in a plastic container containing 2SP transport medium ${ }^{4}$ with $3 \%$ calf serum, and transported in a liquid nitrogen container $\left(-180^{\circ} \mathrm{C}\right)$ to the laboratory where they were stored at $-70^{\circ} \mathrm{C}$. Each specimen was inoculated into two tubes containing HEP-2 cells, incubated at $35^{\circ} \mathrm{C}$, and examined regularly for the presence of cytopathic 
effect. ${ }^{5}$ Isolates were identified using an immunofluorescent staining technique.

Two blood samples were collected by venepuncture at an interval of two to three weeks. Sera were separated and tested with a complement fixation test for HSV group antibodies. ${ }^{6}$

\section{Results}

Age and sex. The patients' ages ranged from 9 months to 66 years with a mean age of 25 years. Of these, 69 $(64 \%)$ were aged 15 or more, and eight $(7 \%)$ were under the age of 5 (Fig. 1). The male to female ratio was $1 \cdot 1$ to one.

Seasonal variation. The prevalence of disease was higher in the months of January to June than in July to December (Fig. 2).

Source of infection. The source of infection was identified in $26(24 \%)$ cases. Of these, nine $(8 \%)$ had been in contact with patients with an active skin HSV infection, and $17(16 \%)$ had HSV lesions on their own lips, nose, or face.

Associated systemic manifestations. In 38 (35\%) patients a mild rhinitis and pharyngitis were present at the time of first examination, and 34 of these also complained of mild malaise, fever, and general aching. A mild to moderate ipsilateral preauricular adenitis was found in $65(60 \%)$ cases. This adenitis was more severe in the first week of infection and subsided gradually in five to 10 days. Cervical and submandibular adenitis developed in $18(17 \%)$ and $12(11 \%)$ patients respectively.

Clinical forms. Moderate or severe disease was observed in $41(38 \%)$ and $16(15 \%)$ patients respectively. Blepharoconjunctivitis (conjunctivitis with lid vesicles and/or ulcers) occurred in $100(93 \%)$ patients. Sixteen of these developed dendritic ulcers and two developed disciform keratitis. In eight $(7 \%)$ cases the disease presented as a follicular conjunctivitis without any typical lid or corneal lesions.

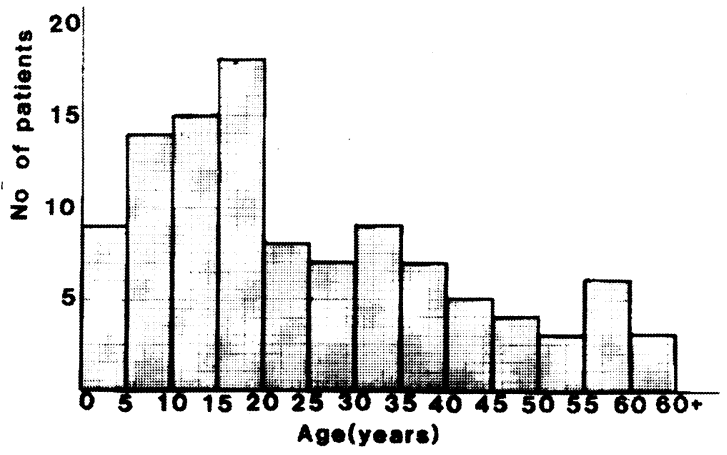

Fig. 1 Age distribution of 108 cases of primary herpes simplex virus ocular infection.

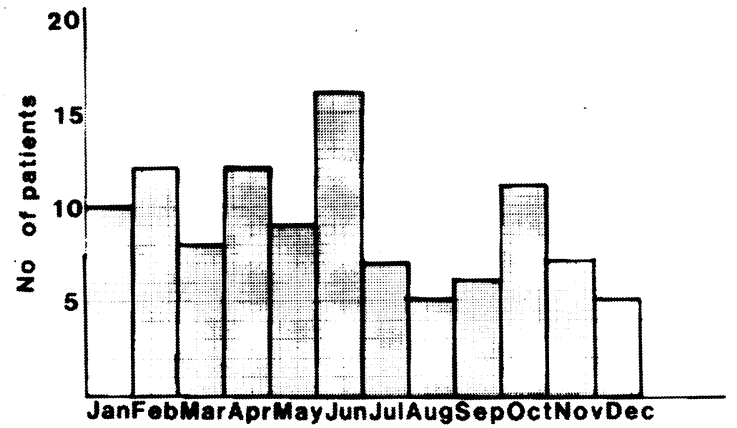

Fig. 2 Seasonal variation of 108 cases of primary herpes simplex virus ocular infection.

Ocular infection was unilateral in $88(81 \%)$ patients and bilateral in $20(19 \%)$ patients. The disease was bilateral at onset in 12 patients and became bilateral within one week of onset in eight patients.

Course of infection. Mild to moderate infections generally lasted for two to three weeks. In severe disease the acute phase of the infection lasted three to five weeks. In $16(15 \%)$ patients a chronic blepharoconjunctivitis developed which lasted for months.

Symptoms. The common symptoms were redness, watering, discharge, itching, irritation, and lid swelling, whereas pain, photophobia, lid vesicles and/or

Table 1 Prevalence and severity of symptoms in 108 cases of primary HSV ocular infection

\begin{tabular}{lllll}
\hline Symptoms & \multicolumn{3}{l}{ Severity } & \\
\cline { 2 - 5 } & Absent & Mild & Moderate & Severe \\
\hline Redness & 18 & 53 & 34 & 3 \\
Watering & 25 & 48 & 30 & 5 \\
Discharge & 27 & 47 & 30 & 4 \\
Irritation and itching & 35 & 58 & 14 & 1 \\
Swelling of lids & 30 & 42 & 26 & 10 \\
Lid vesicles and/or ulcers & 59 & 30 & 19 & 0 \\
Photophobia & 57 & 39 & 10 & 2 \\
Blurred vision & 74 & 30 & 2 & 2 \\
Pain & 80 & 26 & 2 & 0 \\
\hline
\end{tabular}

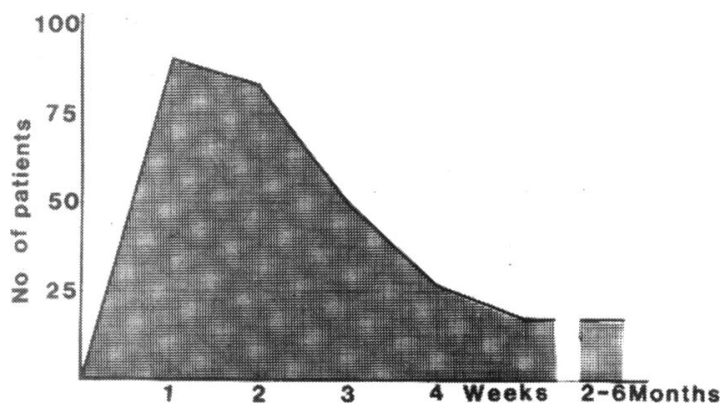

Fig. 3 Prevalence and duration of symptoms in 108 patients with primary herpes simplex virus ocular infection. 
Table 2 Prevalence and severity of signs in 108 cases of primary HSV ocular infection

\begin{tabular}{|c|c|c|c|c|c|}
\hline \multirow[t]{2}{*}{ Area } & \multirow[t]{2}{*}{ Signs } & \multicolumn{4}{|l|}{ Severity } \\
\hline & & Absent & Mild & Moderate & Severe \\
\hline Lids & Vesicles and/or ulcers & 8 & 59 & 31 & 10 \\
\hline \multirow[t]{3}{*}{ Bulbar conjunctiva } & Hyperaemia & 22 & 53 & 30 & 3 \\
\hline & Chemosis & 76 & 24 & 8 & 0 \\
\hline & Ecchymosis & 93 & 14 & 1 & 0 \\
\hline \multirow[t]{5}{*}{ Palpebral conjunctiva } & Hyperaemia & 9 & 43 & 45 & 11 \\
\hline & Ocdema & 10 & 47 & 44 & 7 \\
\hline & Papillac & 2 & 15 & 55 & 36 \\
\hline & Follicles & 7 & 41 & 51 & 9 \\
\hline & Pscudomembrane & 104 & 2 & 2 & () \\
\hline \multirow[t]{5}{*}{ Cornea } & Epithelial punctate keratitis & 72 & 27 & 5 & 4 \\
\hline & Subepithelial punctate keratitis & 87 & 16 & 4 & 1 \\
\hline & Erosion & 101 & 6 & 0 & 1 \\
\hline & Dendritic ulcer & 92 & 12 & 4 & 0 \\
\hline & Disciform keratitis & 106 & 1 & 1 & () \\
\hline
\end{tabular}

ulcers and blurred vision were less frequent (Table 1). Symptoms were most prevalent in the first two weeks but subsided during the next two to three weeks (Fig. 3). However, in $16(15 \%)$ patients mild redness, irritation, discomfort, watering, discharge, and photophobia continued for several months.

Signs. The major signs observed were associated with the lids, conjunctiva, or cornea (Table 2).

On the lids vesicles and/or ulcers occurred in 100 $(93 \%)$ patients (Fig. 4). These were moderate or severe in 41 patients (Table 2). Vesicles were common in the first week of infection, whereas ulcers occurred more commonly in the second week and usually lasted for two to three weeks. However, in seven cases ulcers persisted for four to five weeks. In $16(15 \%)$ patients a chronic blepharitis consisting of mild to moderate lid margin erythema, scales, and meibomitis developed. This chronic blepharitis lasted for months.

The bulbar conjunctiva showed mild to moderate hyperaemia in $83(77 \%)$ and severe hyperaemia in three $(3 \%)$ patients. Mild to moderate chemosis was

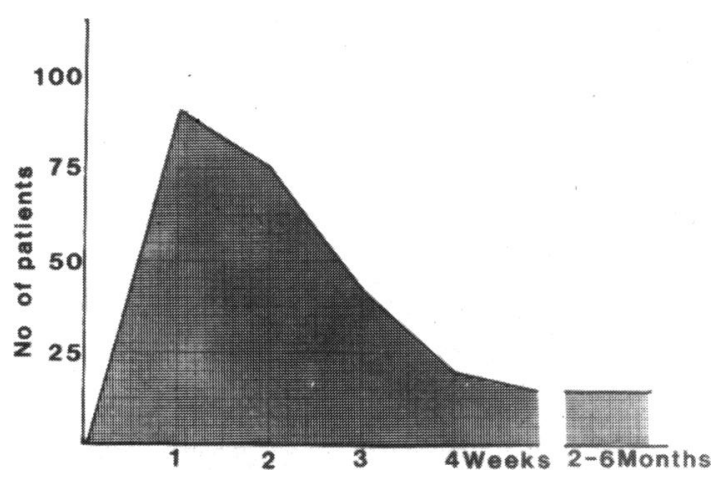

Fig. 4 Prevalence and duration of lid signs in 108 patients with primary herpes simplex virus ocular infection. observed in $32(30 \%)$ patients. Ecchymosis was observed in $15(14 \%)$ patients (Table 2). In the palpebral conjunctiva moderate to severe hyperaemia and oedema were observed in $56(52 \%)$ and $51(47 \%)$ patients respectively. Papillae were found in all except two patients (Table 2 ). The papillary response was moderate or severe in $91(84 \%)$ patients. It was more severe in the upper lid conjunctiva than in the lower and usually lasted for four to eight weeks. In 35 $(32 \%)$ patients a mild to moderate papillary response persisted for six months or more (Fig. 5). Follicular hypertrophy was found in $101(94 \%)$ patients and was moderate to severe in $60(56 \%)$ patients (Table 2). The follicles were small, discrete, and found mainly in the lower lid conjunctiva. In most cases they persisted for four to eight weeks (Fig. 6). However, in $26(24 \%)$ patients small follicles were still present four to six months after the onset of infection (Table 2 ). In four $(4 \%)$ patients a mild to moderate pseudomembrane was present.

Corneal signs comprising punctate keratitis, erosion, dendritic ulcer, or stromal keratitis were

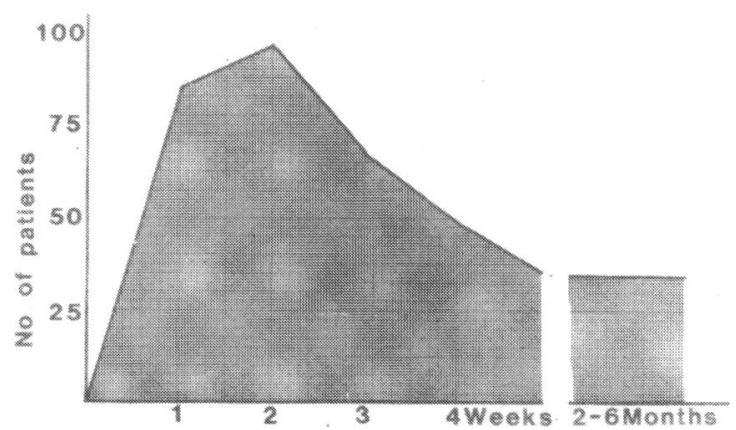

Fig. 5 Prevalence and duration of the conjunctival papillary response in 108 patients with primary herpes simplex virus ocular infection. 


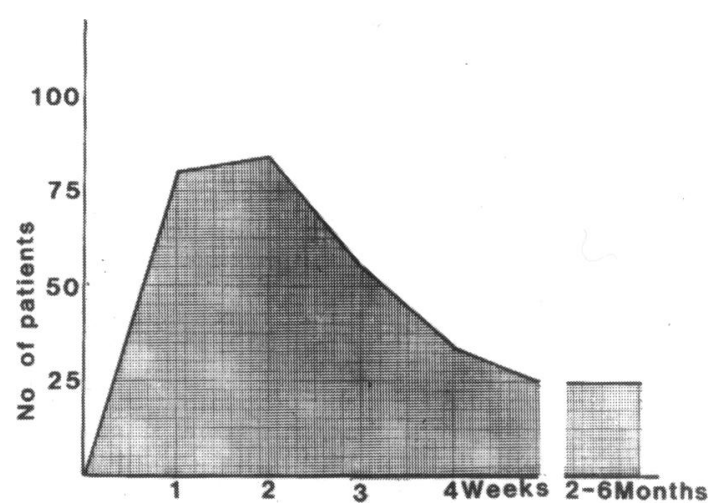

Fig. 6 Prevalence and duration of the conjunctival follicular response in 108 patients with primary herpes simplex virus ocular infection.

found in $36(33 \%)$ patients. A mild to moderate fine epithelial punctate keratitis (EPK) ${ }^{7}$ appeared during the first week of the infection. In most cases this disappeared within three weeks (Fig. 7). In 21 (19\%) patients EPK was followed by subepithelial punctate keratitis (SEPK) ${ }^{7}$ (Table 2). SEPK appeared in the first three weeks of infection and was more prominent during the third and fourth weeks (Fig. 8). In six cases SEPK lasted for several months. Small corneal erosions, which stained with fluorescein, were detected in seven $(6 \%)$ patients. Dendritic ulcers were detected in $16(15 \%)$ patients. These ulcers developed between days 5 and 10 and lasted for one to two weeks. Diffuse stromal keratitis, presenting as disciform keratitis, developed in two $(2 \%)$ patients (Table 2).

Virus isolation. Conjunctival specimens were collected from 69 patients, and HSV was isolated from $42(61 \%)$ patients. Fifty-three specimens were collected during the first week of infection of which 34 $(64 \%)$ were positive. Eight out of 16 specimens $(50 \%)$ collected during the second week were positive.

Antibodies. Forty paired sera were tested for the presence of group-specific HSV antibodies. Fourfold or higher rises in titre were detected in nine out of $40(23 \%)$ of these.

\section{Discussion}

Primary HSV ocular infection can constitute up to $23 \%$ of all cases of acute conjunctivitis presenting at ophthalmic outpatient clinics. ${ }^{89}$ The true prevalence may be much higher, because patients with mild forms of conjunctivitis with a few lid lesions, and those with acute conjunctivitis without characteristic lid or corneal lesions, generally attend their family doctor. Hence, these conditions may remain largely unrecognised, and treated unnecessarily with anti-

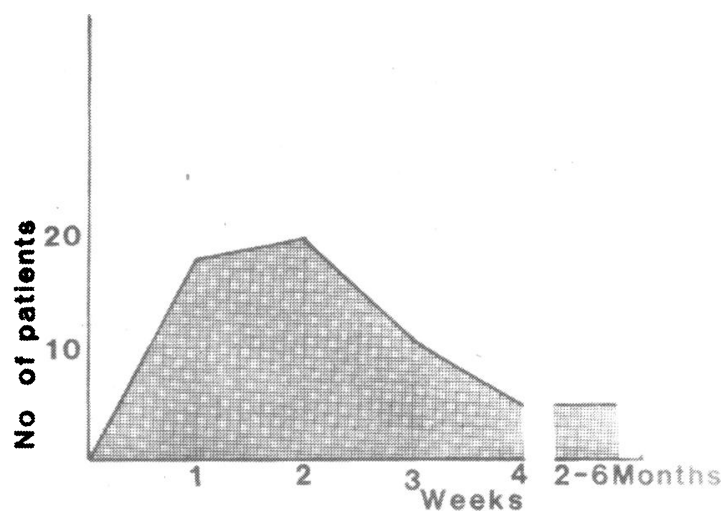

Fig. 7 Prevalence and duration of epithelial punctate keratitis in 108 patients with primary herpes simplex virus ocularinfection.

biotics, or be exposed to the hazards of steroid treatment. ${ }^{8}$

In this series of patients the epidemiological and clinical features of primary HSV ocular infection differed from previous reports. It has been reported that primary ocular HSV infection presents predominantly in two age groups with equal prevalence. ${ }^{\circledR}$ The first consists of children who have been kissed by their infected parents, and the second consists of young adults who have been kissed by their infected partners. In London the age distribution of ocular HSV infection appears to have changed. In a previous study ${ }^{11}$ five out of 17 patients $(29 \%)$ were under the age of 5 , whereas in the present series only eight out of 108 patients $(7 \%)$ were under 5 . In contrast the proportion of cases in adolescents and young adults has increased from $41 \%$ (seven out of 17 ) ${ }^{11}$ to $64 \%$ (69 out of 108) in the present series. It has been reported that the prevalence of antibodies against HSV type 1 in young adults is declining, "indicating that infections in childhood are less common. The decrease which we have observed in the proportion of children with primary HSV ocular infection may be a reflection of this decline. The increased pro-

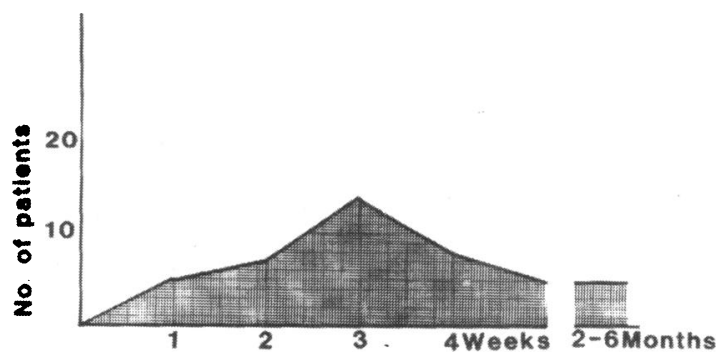

Fig. 8 Prevalence and duration of subepithelial punctate keratitis in 108 patients with primary herpes simplex virus ocular infection. 
portion of cases of primary HSV ocular infection in young adults may be the result of very low rates of infection in childhood.

We observed moderate and severe conjunctivitis and blepharitis in $84 \%$ and $38 \%$ of patients respectively. In previous studies of primary HSV ocular infection in London ${ }^{810}$ and elsewhere ${ }^{12}$ there were no records of the severity of disease to compare with our findings. However, considering the general statements in these reports and our observations in the External Eye Diseases Clinic at Moorfields Eye Hospital during the past two decades (unpublished data) we believe that primary HSV ocular infection is presenting in more severe forms. This increase in the severity of disease in our patients may be also due to a decrease in the prevalence of HSV infection during childhood. Studies have shown that HSV ocular infection is generaly milder in those who have been previously exposed to HSV in the eye or elsewhere. ${ }^{8}$

In $7 \%$ of our patients the disease presented as an acute follicular conjunctivitis without typical lid or corneal lesions. Sporadic cases of HSV follicular conjunctivitis have been reported previously. ${ }^{2101213}$ The largest number of such cases has been found in London, and most of these patients were between 20 and 35 years old. ${ }^{2}$ The clinical features, comprising moderate to severe papillary and follicular responses with or without EPK or SEPK, are similar to those of adenovirus and the early stages of chlamydial ocular infections. It has been reported that HSV may be responsible for up to $21 \%$ of cases of acute conjunctivitis in London. ${ }^{9}$ However, in the absence of routine laboratory investigations for $\mathrm{HSV}$ in cases of acute conjunctivitis or keratoconjunctivitis such cases cannot be correctly diagnosed and treated.

In this study dendritic ulcers and disciform keratitis were found in $16(15 \%)$ and two $(2 \%)$ patients respectively. Patterson and Jones ${ }^{10}$ reported the development of dendritic ulcers and disciform keratitis in one out of 17 patients with primary HSV ocular infection. Our study confirms the observation that dendritic ulcers and disciform keratitis occur in primary as well as recurrent HSV ocular infection.

In the present series $16(15 \%)$ patients developed a chronic blepharoconjunctivitis with mild symptoms and mild to moderate signs consisting of lid margin erythema, scales, meibomitis, papillary, and follicular responses. This lasted for several months. In these patients laboratory investigations showed no evidence of bacterial or allergic aetiology. These findings suggest that HSV may be a cause of chronic blepharitis and blepharoconjunctivitis.

The authors are grateful to colleagues at Moorficlds Eye Hospital for referring the patients and to Miss $U$ Thaker for assistance in laboratory work. The study was supported by a grant from the Department of Health and Social Security through Moorficlds Eyc Hospital.

\section{References}

1 Darougar S, Treharne JD, and Monnickendam MA. Herpes simplex virus infections of the eye. In: Waterson, AP ed. Recent advances in clinical virology. London, Churchill Livingstone, $1980 ; 131-46$.

2 Darougar S, Hunter PA, Viswalingam ND, Gibson JA, Jones BR. Acute follicular conjunctivitis and keratoconjunctivitis due to herpes simplex virus in London. Br J Ophthalmol 1978; 62: 843-9.

3 Darougar S, Viswalingam ND, Treharne JD, Kinnison JR, Jones BR. Treatment of TRIC infection of the eye with rifampicin or chloramphenicol. Br J Ophthalmol 1977; 61: 255-9.

4 Gordon FB, Harper JA, Quan AL, Treharne JD, Dwyer RStC, Garland JA. Detection of Chlamydia (Bedsonia) in certain infections of man. I. Laboratory procedures: comparison of yolk sac and cell culture for detection and isolation. $J$ Infect Dis 1969; 120: 451-62.

5 McSwiggan DA, Darougar S, Rahman AFNS, Gibson JA. Comparison of the sensitivity of human embryo kidney cells, HeLa cells and W138 cells for the primary isolation of viruses from the eye. J Clin Pathol 1975; 28: 410-13.

6 Bradstreet CM, Taylor CED. Technique of complement-fixation test applicable to the diagnosis of virus diseases. Monthly Bulletin of the Ministry of Health and Public Health Laboratory Service 1962; 21: 96-104.

7 Jones BR. Adenovirus infection of the eye in London. Trans Ophthalmol Soc UK 1962; 82: 621-44.

8 Jones BR. The management of ocular herpes. Trans Ophthalmol Soc UK 1959; 79: 425-37.

9 Wishart PK, James C, Wishart MS, Darougar S. Prevalence of acute conjunctivitis caused by chlamydia, adenovirus and herpes simplex virus in an ophthalmic casualty department. $\mathrm{Br} J \mathrm{Oph}$ thalmol 1984; 68: 653-5.

10 Patterson A, Jones BR. The management of ocular herpes. Trans Ophthalmol Soc UK 1967; 87: 59-84.

11 Anonymous. Herpes simplex-changing patterns. (Editorial). Lancet 1981; ii: 1025-6.

12 O’Day D, Jones BR. Herpes simplex keratitis. In: Duane, TD ed. Clinical ophthalmology Hagerstown: Harper and Rowe, 1980, 4: 11-26.

13 Maumenee AE, Hayes GS, Hartman TZ. Isolation and identification of the causative agent in epidemic keratoconjunctivitis (superficial punctate keratitis) and herpetic keratoconjunctivitis. Am J Ophthalmol 1945; 28: 823-39. 